\title{
\begin{tabular}{l|l|l} 
& Jurnal Kependidikan Dasar & Volume :3 \\
& Nomor : 2 \\
& Tahun : 2018
\end{tabular}
}

\section{Penerapan Model Pembelajaran Project Based Learning pada Mata Kuliah Kewirausahan dalam Meningkatkan Hasil Belajar Mahasiswa}

\author{
Susi Damayanti ${ }^{1}$, Bayu Surindra ${ }^{2}$ \\ Universitas Nusantara PGRI Kediri \\ susidamayanti@unpkediri.ac.id, bayusurindra@unpkediri.ac.id
}

\begin{abstract}
ABSTRAK
The purpose of this study is to find out the differences in student learning outcomes both before and after the application of project based learning models in entrepreneurship courses. The type of research used is classroom action research which aims to determine the improvement of student learning outcomes through the application of project based learning learning models in entrepreneurship courses. The subject of this research is Nusantara PGRI Kediri Primary School Teacher Education Study Program at level IV class E which amounts to 33 students, while the objects in this study are the learning outcomes of PGSD students in entrepreneurship courses. The analysis techniques used are descriptive analysis to determine the differences before and after the application of project based learning models in entrepreneurship courses. The results of data processing using SPSS software there is an increase in student learning outcomes and from the results of the significance test data obtained the value of Sig. (2-tailed) is 0,000 <0,05, so it can be concluded that the application of project based learning models in entrepreneurship courses there is a significant difference. Furthermore, the results of student learning completeness also increased from cycle 1 with an average value of $68 \%$, increasing in cycle 2 with an average value of $85.7 \%$.
\end{abstract}

Keywords: project based learning, student learning outcomes

\begin{abstract}
Abstrak
Tujuan dari penelitian ini yaitu ingin mengetahui perbedaan hasil belajar mahasiswa baik sebelum maupun sesudah penerapan model pembelajaran project based learning pada mata kuliah kewirausahaan. Jenis penelitian yang digunakan yaitu penelitian tindakan kelas yang memiliki tujuan untuk mengetahui peningkatan hasil belajar mahasiswa melalui penerapan model pembelajaran project based learning pada mata kuliah kewirausahaan. Yang menjadi subjek penelitian ini yaitu Program Studi Pendidikan Guru Sekolah Dasar Universitas Nusantara PGRI Kediri tingkat IV kelas E yang berjumlah 33 mahasiswa, sedangkan objek dalam penelitian ini yaitu hasil belajar mahasiswa PGSD mata kuliah kewirausahaan. Teknik analisis data yang dipakai yaitu analisi deskriptif untuk mengetahui perbedaan sebelum dan sesudah penerapan model pembelajaran project based learning pada mata kuliah kewirausahaan. Dari hasil pengolahan data dengan menggunakan software SPSS terdapat peningkatan hasil belajar mahasiswa, serta dari hasil uji signifikansi didapatkan data nilai Sig.(2-tailed) adalah 0,000 $<0,05$, sehingga dapat disimpulkan bahwa penerapan model pembelajaran project based learning pada mata
\end{abstract}


kuliah kewirausahaan ada perbedaan yang signifikan. Selanjutnya dari hasil ketuntasan belajar mahasiswa juga mengalami peningkatan dari siklus 1 dengan nilai rata-rata sebesar $68 \%$, meningkat pada siklus 2 dengan nilai rata-rata sebesar $85,7 \%$.

Kata Kunci: project based learning, hasil belajar mahasiswa

\section{PENDAHULUAN}

Pendidikan merupakan suatu hal yang bisa dikategorikan sebagai kebutuhan yang harus dipenuhi oleh manusia tanpa terkecuali, karena dengan adanya pendidikan banyak hal yang akan bisa didapatkan terutama untuk dapat meningkatkan kualitas sumber daya manusia. Dimana untuk saat ini keberhasilan pendidikan dalam suatu negara sangat dipengaruhi oleh kualitas sumber daya manusianya. Hal ini sejalan dengan himbauan dari pemerintah Indonesia bahwa pemerintah mewajibkan masyarakat untuk wajib belajar minimal 12 tahun. Dengan harapan bahwa semakin banyak masyarakat yang berpendidikan, maka diharapkan pula sumber daya manusia menjadi lebih berkualitas. Untuk itu kontribusi semua pihak diperlukan demi mensukseskan terciptanya pendidikan yang berkualitas dan berkelanjutan agar tujuan dari adanya pendidikan itu bisa tercapai.

Didalam dunia pendidikan peran antara pendidik dan peserta didik sangat diperlukan, penggunaan model serta media pembelajaran yang inovatif juga diperlukan untuk menunjang keterlaksanaan pendidikan tersebut. Pendidik berperan dalam menjadi fasilitator demi terciptanya pendidikan yang berkualitas, begitu pula peserta didik atau mahasiswa diharapkan juga berperan aktif dalam proses pembelajaran. Serta pemilihan media dan model pembelajaran yang sesuai juga akan sangat membantu keberlangsungan pembelajaran sehingga pembelajaran bisa berjalan dengan efektif dan efisien.

Pada penelitian ini pemilihan model pembelajaran yang sesuai sangat diperlukan terutama jika diterapkan pada mata kuliah kewirausahaan. Dimana mata kuliah kewirausahaan merupakan salah satu mata kuliah yang pada dasarnya memang harus dimiliki oleh mahasiswa. Dengan harapan jika mahasiswa menguasai kewirausahaan maka saat mahasiswa lulus, mahasiswa diharapkan mampu membuka usaha serta mampu membuka lapangan pekerjaan agar tidak hanya bergantung pada lowongan pekerjaan yang tersedia. Seperti yang diketahui saat ini bahwa lowongan pekerjaan yang tersedia sangat tidak sebanding dengan jumlah angkatan kerja yang ada. Untuk itu dengan dikuasainya kewirausahaan oleh mahasiswa diharapkan mahasiswa bisa lebih mandiri, serta memiliki tingkat kepercayaan diri yang kuat karena bisa mengetahui kelebihan, kekurangan yang dimiliki oleh dirinya.

Penerapan model pembelajaran project based learning dalam mata kuliah kewirausahaan diharapkan dapat memperlancar proses pembelajaran. Model pembelajaran project based learning merupan sebuah model pembelajaran yang menggunakan proyek (kegiatan) 
sebagai inti pembelajaran ${ }^{1}$. Menurut Thomas dkk project based learning (PjBL) adalah model pembelajaran yang memberikan kesempatan kepada guru untuk mengelola pembelajaran di kelas dengan melibatkan kerja proyek ${ }^{2}$. Menurut Trianto, pembelajarn berbasis proyek didefinisikan sebagai suatu pengajaran yang mencoba mengaitkan antara teknologi dengan masalah kehidupan sehari-hari yang akrab dengan siswa, atau proyek sekolah $^{3}$. Dari beberapa pendapat diatas dapat disimuplan bahawa project based learning merupakan suatu kegiatan pembelajaran yang berbasis proyek, dimana mahasiswa dan guru menjalakna suatu proyek yang pelaksanaanya dikaitkan dengan masalah kehidupan sehari-hari.

Menurut Buck Institute for Education ${ }^{4}$ menyebutkan beberapa karakteristik dari project based learning antara lain: 1) mahasiswa

\footnotetext{
${ }^{1}$ Lani Meita Indah Furi, Sri Handayani, dan Shinta Maharani, "EKSPERIMEN MODEL PEMBELAJARAN PROJECT BASED LEARNING DAN PROJECT BASED LEARNING TERINTEGRASI STEM UNTUK MENGINGKATKAN HASIL BELAJAR DAN KREATIVITAS SISWA PADA KOMPETENSI DASAR TEKNOLOGI PENGOLAHAN SUSU," Jurnal Penelitian Pendidikan 35, no. 1 (20 Juli 2018): 49-60-60, https://doi.org/10.15294/jpp.v35i1.13886.

${ }^{2}$ Saerozi, "PENGARUH MODEL PEMBELAJARAN PROJECT BASED LEARNING BERORIENTASI ECOPRENEURSHIP DAN MOTIVASI TERHADAP PENINGKATAN HASIL BELAJAR SISWA PADA MATERI SISTEM PENGELASAN DI SEKOLAH MENENGAH KEJURUAN," Jurnal Pendidikan Teknik Mesin 17, no. 1 (2017), https://journal.unnes.ac.id/nju/index.php/JPTM/arti cle/view/12735.

${ }^{3}$ Trianto, Model Pembelajaran Terpadu (Jakarta: Bumi Aksara, 2011).

${ }^{4}$ I. Made Wirasana Jagantara dkk., "Pengaruh model pembelajaran berbasis proyek (project based learning) terhadap hasil belajar biologi ditinjau dari gaya belajar siswa sma," Jurnal Pendidikan dan Pembelajaran IPA Indonesia 4, no. 1 (2014).
}

sebagai pembuat keputusan dan membuat kerangka kerja; 2) terdapat masalah yang pemecahannya tidak ditentukan sebelumnya; mahasiswa sebagai perancang proses untuk mencapai hasil; 4) mahasiswa bertanggungjawab mendapatkan dan mengelola informasi yang dikumpulkan; 5) melakukan evaluasi secara kontinu; 6) mahasiswa secara teratur melihat kembali apa yang mereka kerjakan; 6) hasil akhir berupa produk dan di evaluasi kualitasnya; dan 7) kelas memiliki atmosfer yang memberi toleransi atas kesalahan dan perubahan. Dari karakteristikkarakteristik yang disebutkan diatas diketahui bahwa memamang peran aktif mahasiswa sangat diperlukan untuk menciptakan suatu keadaan dimana proyek yang menjadi tugas dan akan dilakukan oleh mahasiswa tersebut bisa berjalan dengan baik. Untuk itu saling kerjasama dalam menyelesaikan tugas sangatlah diperlukan agar tujuan dari project based learning itu dapat terlaksana dengan baik. 




Gambar 1. Sintaks dan proyek business plan mahasiswa Prodi PGSD

Langkah-langkah atau Sintaks penerapan project based learning menurut Mergendoller, et $\mathrm{al}^{5}$, antara lain: 1) project planning (perencanaan proyek); 2) project launch (pelaksanaan proyek); 3) guided inquiry and product creation (penyelidikan terbimbing dan pembuatan produk); and 4) project

\footnotetext{
${ }^{5}$ John R. Mergendoller dkk., "Pervasive management of project based learning: Teachers as guides and facilitators," Handbook of Classroom Management: Research, Practice, and Contemporary Issues, Mahwah, NJ: Lawrence Erlbaum, Inc, 2006, 583-615.
}

conclution (kesimpulan proyek).Dari langkah-langkah diatas dimulai kegiatan merencanakan, melaksanakan kegiatan, menyelidiki dan membuat produk dari proyek yang saudah ditentukan sebelumnya, serta membuat kesimpulan dari kegiatan yang sudah dilakukan, pelaksanaannya harus dilakukan secara berurutan agar tercptanya suatu kegiatan yang beruntun dan tidak menyimpang dari langkahlangkah yang sudah ditetapkan. Dalam hal ini dosen sebagai 
pembimbing memiliki peran yang penting untuk dapat mengarahkan mahasiswa dalam melaksanakan model pembelajaran project based learning.

Keunggulan dalam penerapan model pembelajaran project based learning menurut Kurniasih ${ }^{6}$, antara lain: 1) meningkatkan motivasi belajar peserta didik untuk belajar mendorong kemampuan mereka untuk melakukan pekerjaan penting dan mereka perlu dihargai; 2) meningkatkan kemampuan pemecahan masalah; 3) membuat peserta didik menjadi lebih aktif dan berhasil memecahkan problemproblem yang komplekas; 4) meningkatkan kolaborasi; 5) mendorong peserta didik untuk mengembangkan dan mempraktikkan keterampilan komunikasi; 6) meningkatkan keterampilan peserta didik dalam mengelola sumber; 7) memberikan pengalaman kepada peserta didik dalam pembelajaran dan praktik dalam mengorganisasi proyek dan membuat alokasi waktu dan sumbersumber lain seperti perlengkapan untuk menyelesaiakn tugas; 8) menyediakan pengalaman belajar yang melibatkan peserta didik secara kompleks dan dirancang berkembang sesuai dunia nyata; 9) melibatkan para peserta didik untuk belajar mengambil informasi dan menunjukkan pengetahuan yang dimiliki; dan 10) membuat suasana belajar menjadi menyenangkan, sehingga peserta didik maupun pendidik menikmati proses pembelajaran.

\footnotetext{
${ }^{6}$ Maya Nurfitriyanti, “Model Pembelajaran Project Based Learning terhadap Kemampuan Pemecahan Masalah Matematika," Formatif: Jurnal IImiah Pendidikan MIPA 6, no. 2 (2016).
}

Selanjutnya selain adanya keunggulan dalam penerapan model pembelajaran project based learning, terdapat juga kelemahan-kelemahan dalam penerapan model pembelajaran project based learning menurut Sani ${ }^{7}$, antara lain: 1) membutuhkan banyak waktu untuk menyelesaikan masalah dan menghasilkan produk; 2) membutuhkan biaya yang cukup; 3) membutuhkan guru yang terampil dan mau belajar; 4) membutuhkan fasilitas, peralatan, dan bahan yang memadai; 5) tidak sesuai untuk siswa yang mudah menyerah dan tidak memiliki pengetahuan serta keterampilan yang dibutuhkan; dan 6) kesulitan melibatkan semua siswa dalam kerja kelompok.

Penerapan model pembelajaran project based learning menekankan pada keaktifan mahasiswa dalam menyelesaikan suatu permasalahan berupa proyek. Dengan adanya penerapan model pembelajaran project based learning pada mata kuliah kewirausahaan yang menekankan pada proyek berupa kegiatan mahasiswa dalam mengembangkan jiwa wirausaha diharapkan mampu memberikan pengalaman yang berarti bagi mahasiswa terutama dimana saat mahasiswa melakukan praktek kewirausahaan. Praktek kewirausahaan yang dilakukan berupa membuat serta mempraktekkan business plan yang disusun oleh mahasiswa. Dari proyek business plan mahasiswa diminta untuk membuat rencana produk mulai dari:1) konsep bisnis; 2) deskripsi bisnis; 3) strategi bisnis; 4) analisis persaiangan: 5)rencana

\footnotetext{
${ }^{7}$ Nurfitriyanti.
} 
desain dan pengembangan; 6) rencana operasi dan manajemen; 7) analisis rencana keuangan; serta 8) laporan kegiatan. Praktek kewirausahan tersebut dilakukan oleh mahasiswa Program Studi Pendidikan Guru Sekolah Dasar (PGSD) tingkat IV (empat).

Selanjutnya dari langkahlangkah yang ada diatas dalam palaksanaan model pembelajaran project based learning pada Program studi Pendidikan Guru Sekolah Dasar di Universitas Nusantara PGRI Kediri dapat dijelaskan sebagai berikut:

Dari sintaks serta proyek business plan yang akan dilaksanakan oleh mahasiswa pada mata kuliah kewirausahaan oleh mahasiswa Prodi PGSD dilaksanakan sesuai dengan rencana yang saudah ditentukan sebelumnya, sehingga nantinya akan diperoleh hasil kehiatan yang maksimal dan memauaskan. Terutama hasil belajar mahasiswa serta [engalaman yang diperoleh mahasiswa dalam pengimplementasian business plan yang sudah dibuat sebelumnya.

Berikut ini adalah konsep meningkatkan hasil belajar mahsiswa, yaitu:

Dengan penerapan model pembelajaran project based learning pada mata kuliah kewirausahaan diharpakan hasil belajar mahasiswa meningkat. Dimana keberhasilan project based learning bergantung pada peran dosen serta partisipasi aktif masiswa untuk dalam proses pembelajaran.

\section{METODE PENELITIAN}

Jenis penelitian yang diterapkan yaitu clasroom action research (penelitian tindakan kelas). Penelitian tindakan kelas merupakan suatu penelitian reflektif yang bersiklus (berdaur ulang) yang dilakukan oleh pendidik (guru/dosen) dan tenaga kependidikan lainnya (kepala sekolah/pengawas sekolah / widyaiswara, dan lain-lain) untuk memecahkan masalah di bidang pendidikan ${ }^{8}$.

Subjek penelitian ini yaitu mahasiswa Program Studi Dekolah Dasar tingkat IV yang berjumlah 33 mahasiswa. Dalam penelitian ini peneliti sebagai dosen mata kuliah

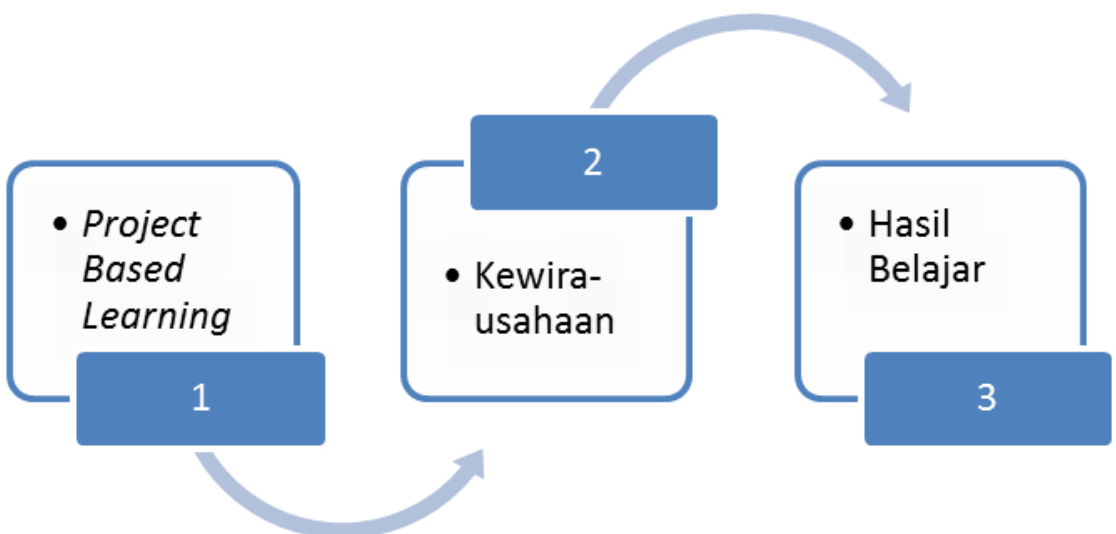

Gambar 2 Konsep project based learning

penerapan model pembelajaran project based learning pada mata kuliah kewirausahaan dalam

\footnotetext{
${ }^{8}$ Saur Tampubolon, Penelitian Tindakan Kelas Sebagai Pengembangan Profesi Pendidik dan Keilmuan (Jakarta: Erlangga, 2014).
} 
Tabel 1. Hasil belajar mahasiswa PGSD tingkat IV sebelum dan sesudah penerapan model pembelajaran project based learning

Paired Samples Statistics

\begin{tabular}{|ll|r|r|r|r|}
\hline & Mean & $\mathrm{N}$ & \multicolumn{1}{c|}{$\begin{array}{c}\text { Std. } \\
\text { Deviation }\end{array}$} & $\begin{array}{c}\text { Std. Error } \\
\text { Mean }\end{array}$ \\
\hline Pair 1 & sebelum PjBL & 67.64 & 33 & 8.842 & 1.539 \\
& sesudah PjBL & 85.67 & 33 & 9.276 & 1.615 \\
\hline
\end{tabular}

kewirausahaan, serta objek penelitian ini yaitu hasil belajar mahasiswa PGSD mata kuliah kewirausahaan.

Analisis data yang digunakan yaitu analisis deskriptif hal itu digunakan untuk mengetahui komparatif hasil belajar mahasiswa antara sebelum penerapan dan sesudah penerapan model pembelajaran project based learning. Uji komparatif merupakan dugaan ada atau tidaknya perbedaan secara signifikan nilai-nilai dua kelompok atau lebih? .

Selain untuk mengetahui perbedaan hasil belajar belajar dengan membandingkan pembelajaran tiap sikluasnya, dalam penelitian ini juga menggunakan bantuan software SPSS untuk melakukan pengujian komparatif dengan tujuan untuk mengetahui taraf signifikansi dalam penerapan model pembelajaran project based learning.

\section{HASIL DAN PEMBAHASAN}

Berikut ini adalah data yang diperoleh dari hasil penelitian dalam penerapan model pembelajaran project based learning pada mata kuliah kewirausahan dalam meningkatkan hasil belajar mahasiswa.

Tabel hasil perhitungan statistik dengan Software SPSS diatas untuk mengetahui hasil belajar rata-rata mahasiswa baik sebelum mapun sesudah penerapan model pembelajaran project based learning. Dari tabel diatas diketahui bahwa hasil belajar rata-rata yang diperoleh mahasiswa sebelum penerapan model pembelajaran project based learning adalah sebesar 67,64, selanjutnya setelah penerapan model pembelajaran project based learning hasil belajar mahasiswa rata-rata meningkat menjadi $85,67 \%$.

Tabel 2. Hubungan sebelum dan sesudah penerapan model pembelajaran project based learning

Paired Samples Correlations

\begin{tabular}{|ll|r|r|r|}
\hline & $\mathrm{N}$ & Correlation & \multicolumn{1}{c|}{ Sig. } \\
\hline Pair 1 & $\begin{array}{l}\text { sebelum PjBL \& sesudah } \\
\text { PjBL }\end{array}$ & 33 & .468 & .006 \\
\hline
\end{tabular}

Dalam tabel 2 yaitu tabel

${ }^{9}$ Sugiyono, MetodePenelitian Pendidikan (Bandung: hubungan atau korelasi untuk Alfabeta, 2010). mengetahui besar maupun kecilnya 
Tabel 3. Signifikansi penerapan model pembelajaran project based learning

Paired Samples Test

\begin{tabular}{|c|c|c|c|c|c|c|c|c|}
\hline & \multicolumn{5}{|c|}{ Paired Differences } & \multirow[b]{3}{*}{$\mathrm{t}$} & \multirow[b]{3}{*}{$\mathrm{df}$} & \multirow{3}{*}{$\begin{array}{c}\text { Sig. } \\
(2- \\
\text { tailed }\end{array}$} \\
\hline & \multirow{2}{*}{$\begin{array}{c}\text { Mea } \\
\mathrm{n}\end{array}$} & \multirow{2}{*}{$\begin{array}{c}\text { Std. } \\
\text { Deviati } \\
\text { on }\end{array}$} & \multirow{2}{*}{$\begin{array}{l}\text { Std. } \\
\text { Error } \\
\text { Mean }\end{array}$} & \multicolumn{2}{|c|}{$\begin{array}{c}95 \% \\
\text { Confidence } \\
\text { Interval of the } \\
\text { Difference }\end{array}$} & & & \\
\hline & & & & Lower & Upper & & & \\
\hline $\begin{array}{ll}\text { Pair } & \text { sebelum PjBL - } \\
1 & \text { sesudah PjBL }\end{array}$ & $\begin{array}{r}18.03 \\
0\end{array}$ & 9.352 & 1.628 & $\begin{array}{r}21.34 \\
7 \\
\end{array}$ & $\begin{array}{r}14.71 \\
4 \\
\end{array}$ & $\begin{array}{r}11.07 \\
5 \\
\end{array}$ & 32 & .000 \\
\hline
\end{tabular}

hubungan atau korelasi penerapan model pembelajaran project based learning. Dari tabel diatas didapatkan data hubungan atau korelasi penerapan model pembelajaran project based learning yaitu sebesar 0,468 atau sebesar $47 \%$.

Tabel signifikansi 3 dipergunakan untuk mengetahui perbedaan hasil belajar mahasiswa dengan penerapan model pembelajaran project based learning. Untuk mengetahui ada atau tidak adanya perbedaan dalam penerapan model pembelajaran project based learning bisa dilihat pada kolom Sig.(2-tailed), dimana jika nilai Sig.(2tailed) kurang dari 0,05 maka penerapan model pembelajaran project based learning dikatakan memiliki perbedaan yang signifikan. Sedangkan jika pada kolom Sig.(2tailed) lebih dari 0,05 maka penerapan model pembelajaran project based learning tidak memiliki perbedaan yang signifikan.

Dari hasil tabel 3 diketahui nilai Sig.(2-tailed) adalah 0,000 sehingga kurang dari 0,05, maka dapat disimpulkan bahwa penerapan model pembelajaran project based learning pada mata kuliah kewirausahaan ada perbedaan yang signifikan dalam mencari hasil belajar mahasiswa. Setelah diterapkannya model pembelajaran project based learning pada magta kuliah kewirausahaan, hasil belajar mahasiswa mengalami peningkatan yang signifikan.

Selanjutnya untuk mengetahui ketuntasan hasil belajar mahasiswa pada setiap siklusnya dapat diketahui dari gambar 2 .

Dari gambar 2 diketahui bahwa hasil belajar mahasiswa pada mata kuliah kewirausahaan mengalami peningkatan dari siklus 1 ke siklus 2 . Ketuntasan hasil belajar mahasiswa pada mata kuliah kewirausahaan pada siklus 1 diketahui sebesar 68\%, sedangkan ketuntasan hasil belajar mahasiswa pada mata kuliah kewirausahaan pada siklus 2 diketahui mengalami peningkatan yaitu menjadi 85,7\%. Dari ketuntasan hasil belajar mahasiswa pada mata kuliah kewirausahaan pada siklus 1 diketahui bahwa terdapat 15 mahasiswa yang tidak tuntas, selanjutnya dilakukan pembelajaran lanjutan pada siklus 2, dimana pada siklus 2 diketahui bahwa hanya terdapat 4 mahasiswa yang tidak tuntas. Meskipun demikian masih dapat memenuhi ketuntasan klasikal hasil belajar mahasiswa yaitu sebesar 


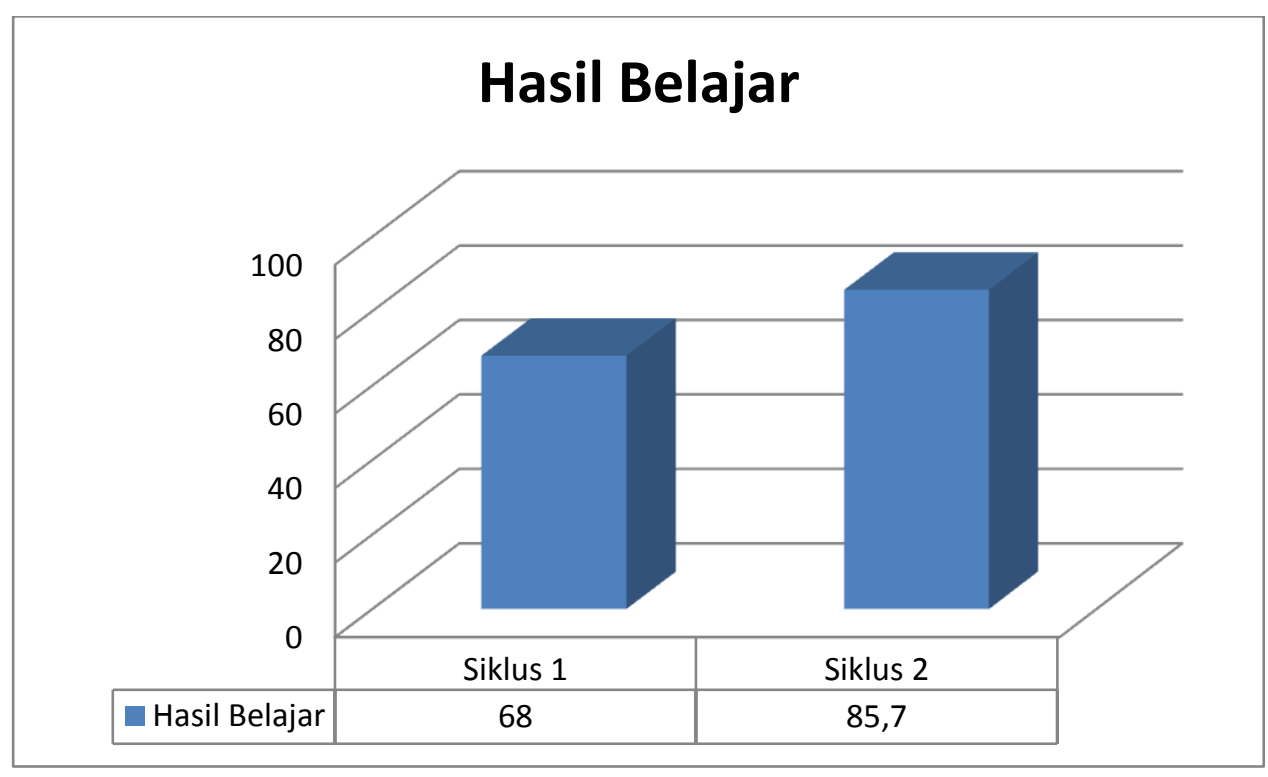

Gambar 2. Ketuntasan Hasil Belajar Mahasiswa dengan penerapan model pembelajaran project based learning

85\%, sehingga penelitian dihentikan pada siklus 2. Karena penerapan model pembelajaran project based learning terbukti dapat meningkatkan hasil belajar mahasiswa.

\section{KESIMPULAN}

Dari hasil penelitian yang dilakukan yaitu untuk mengetahui penerapan model pembelajaran project based learning pada mata kuliah kewirausahaan dalam meningkatkan hasil belajar mahasiswa Prodi PGSD terbukti dapat meningkatkan hasil belajar mahasiswa. Hal tersebut dapat diketahui dari hasil pengolahan data dengan menggunakan software SPSS terdapat peningkatan hasil belajar mahasiswa, serta dari hasil uji signifikansi didapatkan data nilai Sig.(2-tailed) adalah 0,000. Sehingga kurang dari 0,05, maka dapat disimpulkan bahwa penerapan model pembelajaran project based learning pada mata kuliah kewirausahaan ada perbedaan yang signifikan dalam mencari hasil belajar mahasiswa. Selanjutnya dari hasil ketuntasan belajar mahasiswa juga mengalami peningkatan dari siklus 1 dengan nilai rata-rata sebesar 68\%, meningkat pada siklus 2 dengan nilai rata-rata sebesar $85,7 \%$.

\section{REFERENSI}

Furi, Lani Meita Indah, Sri Handayani, dan Shinta Maharani. "EKSPERIMEN MODEL PEMBELAJARAN PROJECT BASED LEARNING DAN PROJECT BASED LEARNING TERINTEGRASI STEM UNTUK MENGINGKATKAN HASIL BELAJAR DAN KREATIVITAS SISWA PADA KOMPETENSI DASAR TEKNOLOGI PENGOLAHAN SUSU." Jurnal Penelitian Pendidikan 35, no. 1 (20 Juli 2018): 49-60-60.

https://doi.org/10.15294/jpp.v35i 1.13886.

Jagantara, I. Made Wirasana, Putu Budi Adnyana, Ni Luh Putu Manik Widiyanti, dan S. Si. "Pengaruh model pembelajaran berbasis proyek (project based learning) terhadap hasil belajar biologi ditinjau dari gaya belajar siswa sma." Jurnal Pendidikan dan Pembelajaran IPA Indonesia 4, no. 1 (2014). 
Mergendoller, John R., Thom Markham, Jason Ravitz, dan John Larmer. "Pervasive management of project based learning: Teachers as guides and facilitators." Handbook of Classroom Management: Research, Practice, and Contemporary Issues, Mahwah, NJ: Lawrence Erlbaum, Inc, 2006, 583-615.

Nurfitriyanti, Maya. "Model Pembelajaran Project Based Learning terhadap Kemampuan Pemecahan Masalah Matematika." Formatif: Jurnal Ilmiah Pendidikan MIPA 6, no. 2 (2016).

Saerozi. "PENGARUH MODEL

PEMBELAJARAN PROJECT BASED

LEARNING BERORIENTASI

ECOPRENEURSHIP DAN MOTIVASI

TERHADAP PENINGKATAN HASIL

BELAJAR SISWA PADA MATERI

SISTEM PENGELASAN DI

SEKOLAH MENENGAH

KEJURUAN." Jurnal Pendidikan

Teknik Mesin 17, no. 1 (2017).

https://journal.unnes.ac.id/nju/in dex.php/JPTM/article/view/1273

5.

Sugiyono. MetodePenelitian Pendidikan.

Bandung: Alfabeta, 2010.

Tampubolon, Saur. Penelitian Tindakan

Kelas Sebagai Pengembangan

Profesi Pendidik dan Keilmuan.

Jakarta: Erlangga, 2014.

Trianto. Model Pembelajaran Terpadu.

Jakarta: Bumi Aksara, 2011. 